\title{
Capacitance Scaling Based Energy Efficient Vedic Divider using Paravartya Yojayet on 28nm FGPA
}

\author{
Shivani Madhok ${ }^{1}$, Kavita Goswami ${ }^{1}$, Tanesh Kumar ${ }^{2}$ \\ ${ }^{1}$ ECE Department, Chitkara University, Chandigarh, India \\ ${ }^{2}$ Indus University, Karachi, Pakistan \\ ${ }^{1}$ \{shivanimadhok0@gmail.com, \\ kavita.goswami@chitkara.edu.in\} \\ ${ }^{2}\{$ tanesh.nustegmail.com\}
}

\begin{abstract}
$\boldsymbol{A} \boldsymbol{b}$ stract-In this paper, we have designed an energy efficient Vedic Divider using an ancient Vedic mathematics technique known as "ParavartyaYojayet". ParavartyaYojayet is a Sanskrit name which means transpose and adjust. Vedic mathematical formulas are used to solve tedious and cumbersome arithmetic operations. Today's world demands implementation of techniques which take lesser time and are energy efficient so we have designed a Vedic divider to solve long divisions in seconds. Our design consists of 2 inputs for dividend and divisor and 2 outputs that are remainder and quotient. Many researchers have done research work on Vedic mathematics to solve DSP operations using Urdhava-Triyagbhayam multiplication sutra, to design asynchronous Vedic DSP processor core and lots more. In our paper we have implemented our code on Xilinx ISE Design Suite 14.2 and results were tested on 28nm FPGA platform. We have done power analysis by varying frequencies and capacitance to make our Vedic divider energy efficient. Analysis results that the maximum power is consumed at $2.2 \mathrm{GHz}$ and minimum power is consumed at $1.2 \mathrm{GHz}$. In respect of capacitance maximum power is consumed at $100 \mathrm{pF}$ and minimum power is consumed at $20 \mathrm{pF}$.
\end{abstract}

Keywords. Paravartyayojayet, Vedic mathematics, FGPA, Energy Efficient, Vedic Divider 


\section{Gyancity Journal of Engineering and Technology, \\ Vol.2, No.1, pp. 19-33, January 2016 \\ ISSN: 2456-0065 DOI: 10.21058/gjet.2016.2103}

\section{Introduction}

Ancient mathematics is known as Vedic mathematics [1-2]. Vedic mathematics is part of four Vedas (books of wisdom)[3].Vedic mathematics deals with various Vedic mathematical formulae and their applications to carry out tedious and cumbersome arithmetic operations[4].the Vedic mathematics sutra are from Vedas that were used by our ancient scholars to make mathematical calculations faster, when there were no calculators and computers[5]. This Vedic mathematics can be used to solve algebra easily [5]. Figure 1 represents the division of sutras. Sutras can be used for arithmetic computation and also for algebra computation. Figure 2 shows the list of 18 sutras. These sutras cover all fields of mathematics geometry, arithmetic etc. research is been carried out in many areas. With the help of these sutras we can easily solve the complex calculations. These sutras are very helpful in solving calculus, geometry problems. Application of Vedic sutras spares a lot of time and effort in solving problems.

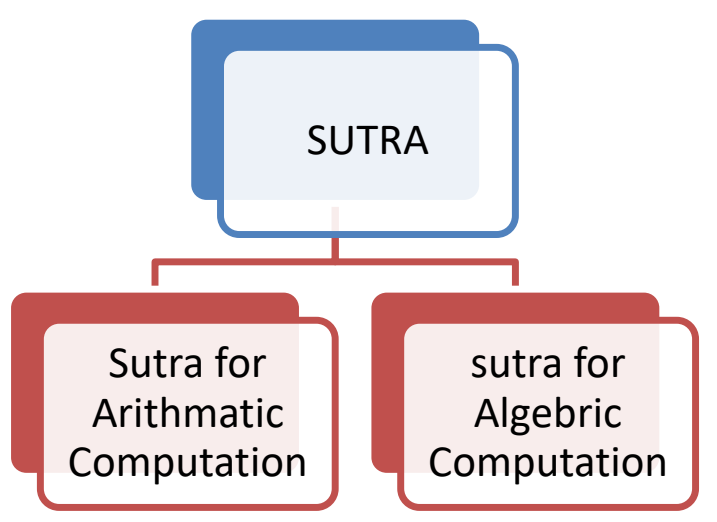

Fig. 1. Types of Sutra (Formula) in Vedic Mathematics

Many papers have been published using Vedic mathematics for different applications. A paper was published which includes DSP operations based on ancient Vedic mathematics using Vedic Urdhava-Triyagbhayam multiplication sutra [6]. A design of an 8 bit fixed point, asynchronous Vedic DSP processor core has also been studied [7]. Today's world demands implementation of techniques which take lesser time and is energy efficient so we have designed a Vedic divider. other researchers have also performed there research work in the field of Vedic mathematics like implementation of 4*4 multiplier using Urdhva-Tiryakbhyam in 45nm technology[8], another division architecture using another Vedic technique known as `Dhwajam'[9]. With the enrichment of new technology there is a huge demand of energy efficiency. Keeping this in our mind we have designed a Vedic divider which is energy efficient and we have tested in 
Gyancity Journal of Engineering and Technology,

Vol.2, No.1, pp. 19-33, January 2016

ISSN: 2456-0065 DOI: 10.21058/gjet.2016.2103

on 28nm FGPA family Kintex-7. Power analysis has been done to make it energy efficient by varying values of capacitance and frequencies.

\begin{tabular}{|c|}
\hline •Ekadhikena Purvena \\
\hline - Nikhilam navatascaramam Dasatah \\
\hline -Urdhva - tiryagbhyam \\
\hline -Paravartya Yojayet \\
\hline - Sunyam Samya Samuccaye \\
\hline -Anurupye - Sunyamanyat \\
\hline -Sankalana - Vyavakalanabhyam \\
\hline •Puranapuranabhyam \\
\hline -Calana - Kalanabhyam \\
\hline •Ekanyunena Purvena \\
\hline -Anurupyena \\
\hline -Adyamadyenantya - mantyena \\
\hline - Yavadunam Tavadunikrtya Varganca Yojayet \\
\hline -Antyayor Dasakepi \\
\hline - Antyayoreva \\
\hline •Lopana Sthapanabhyam \\
\hline -Vilokanam \\
\hline • Gunita Samuccayah \\
\hline
\end{tabular}

Fig. 2. List of Vedic Formula (Sutra) in Vedic Mathematics

LVCMOS IO standard is used to design FPGA based Thermal Aware Energy Efficient Vedic Multiplier based on Urdhva Tiryagbhyam [10]. In order to achieve speed and high performance in addition to energy efficiency, HSTL IO standard is also used along with LVCMOS for design of energy efficient Vedic multiplier based on Urdhva Tiryagbhyam [11]. Capacitance scaling is one of the best energy efficient technique for FPGA based VLSI design. Earlier capacitance scaling is also used to design of energy efficient ROM [12], energy efficient UART [13] and power optimized register [14]. Here we are going to utilize the benefit of capacitance scaling for this Vedic Divider based on Vedic formula of Parvartya Yojayet. 


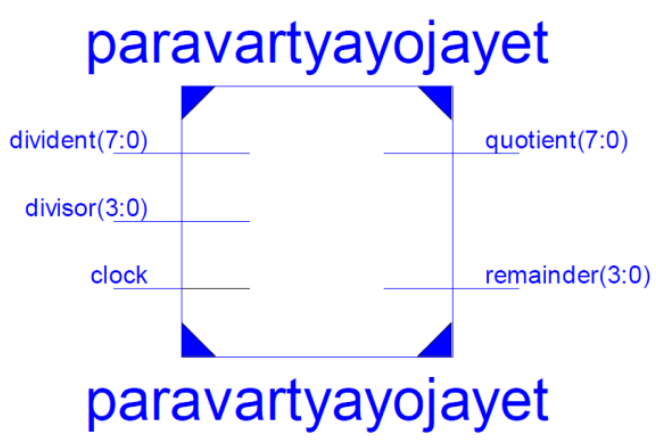

Fig. 3. Top Level Schematic of ParavartyaYojayet Sutra Based Vedic Divider

This Vedic divider has three inputs and two outputs as shown in Figure 3. One input is clock pulse. Second input is 8-bit dividend. Third input is 4-bit divisor. First output is 8-bit quotient and second output is 4-bit remainder. For example, if dividend is 254 ( 8 'b11111110) and divisor is $12\left(4^{\prime} \mathrm{b} 1100\right)$ then quotient is $21\left(8^{\prime} \mathrm{b} 00010101\right)$ and remainder is 2 (4'b0010). Our paper deals with ParavartyaYojayet, this is a Sanskrit name meaning transpose and adjust. In this work a Vedic divider is designed using ParavartyaYojayet. The code has been implemented in Xilinx ISE Design Suite 14.2 and results were tested on 28nm FPGA platform. All our work is done on 28nm FPGA kintex-7. ParvartyaYojayet algorithm is implemented to develop a high performance divider and static timing analysis is also done on Vedic divider [3]. In this paper, we have tried to make an energy efficient ParvartyaYojayet Vedic divider with 2 inputs and 2 outputs.

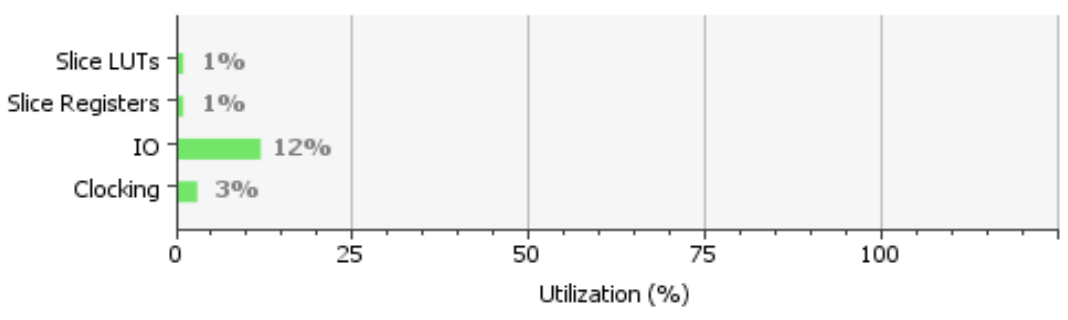

Fig. 4. FPGA Resource Utilization by Paravartya Yojayet Based Vedic Divider

This design is using only $1 \%$ Slice LUTs, $1 \%$ Slice Registers, $12 \%$ IO and 3\% clocking available on Kintex-7 FPGA. 
Gyancity Journal of Engineering and Technology,

Vol.2, No.1, pp. 19-33, January 2016

ISSN: 2456-0065 DOI: 10.21058/gjet.2016.2103

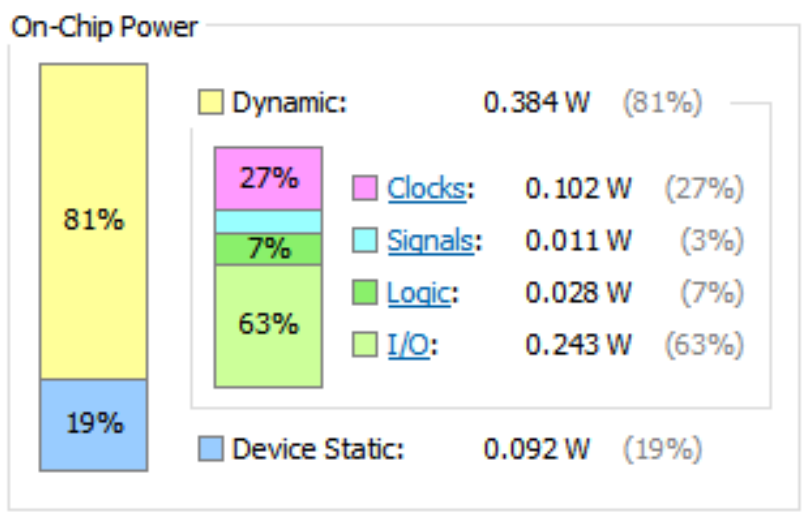

Fig. 5. On-Chip Power Dissipation of Our Design on Kintex-7 FPGA

When we are doing on-chip power analysis of Vedic divider on Kintex-7 FPGA, then this design is using $19 \%$ Static power and $81 \%$ dynamic power. Out of $81 \%$ dynamic power, $27 \%$ is clock power, $3 \%$ is signals power, $7 \%$ is logic power and $63 \%$ IO power.

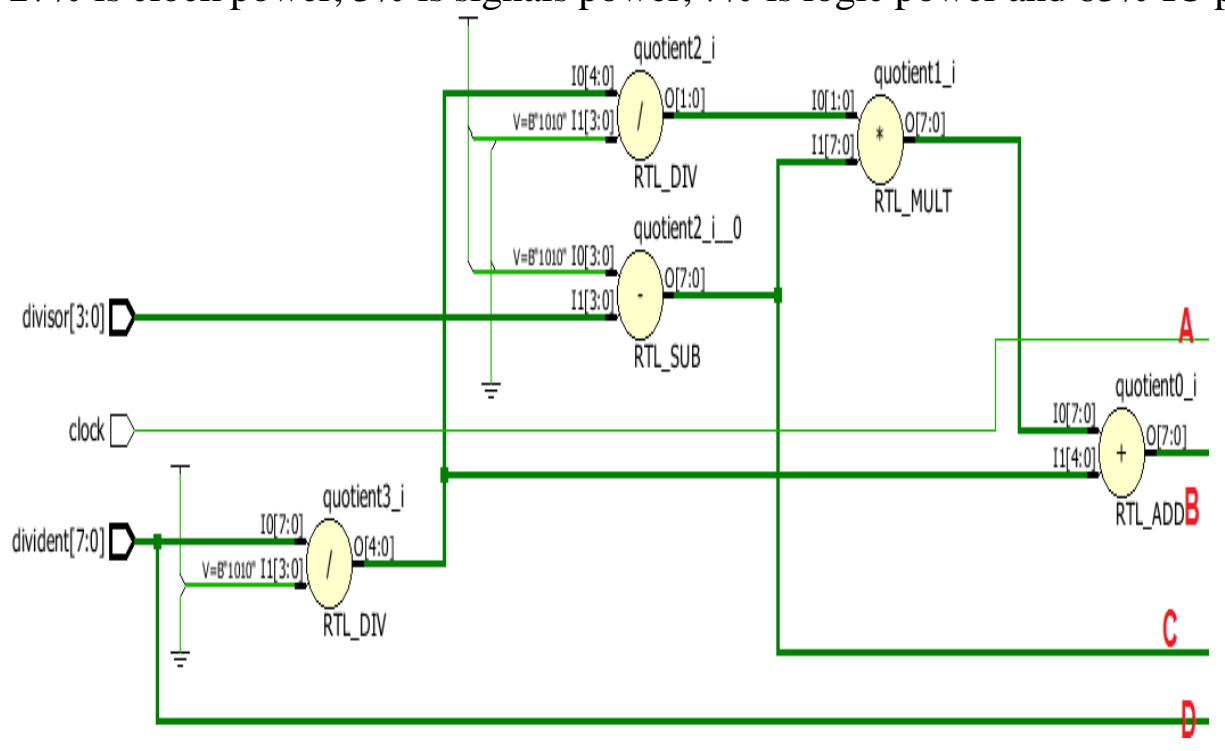

Fig. 6. RTL Schematic of Parvartya Yojayet: Part I

Step 1: Divide 254 by 12.

Step 2: We separate last digit 4 (i.e. 254\%10) from dividend 254 for remainder and 25 (i.e. 254/10) for later division process as shown in Figure 6. 


\section{Gyancity Journal of Engineering and Technology, \\ Vol.2, No.1, pp. 19-33, January 2016 \\ ISSN: 2456-0065 DOI: 10.21058/gjet.2016.2103}

Step 3: We minus divisor 12 from 10 and get -2 . Multiply this -2 by first digit of 25 i.e. 2 and we finally get -4 and add -4 to 25 and get 21 as quotient as shown in Figure 6.

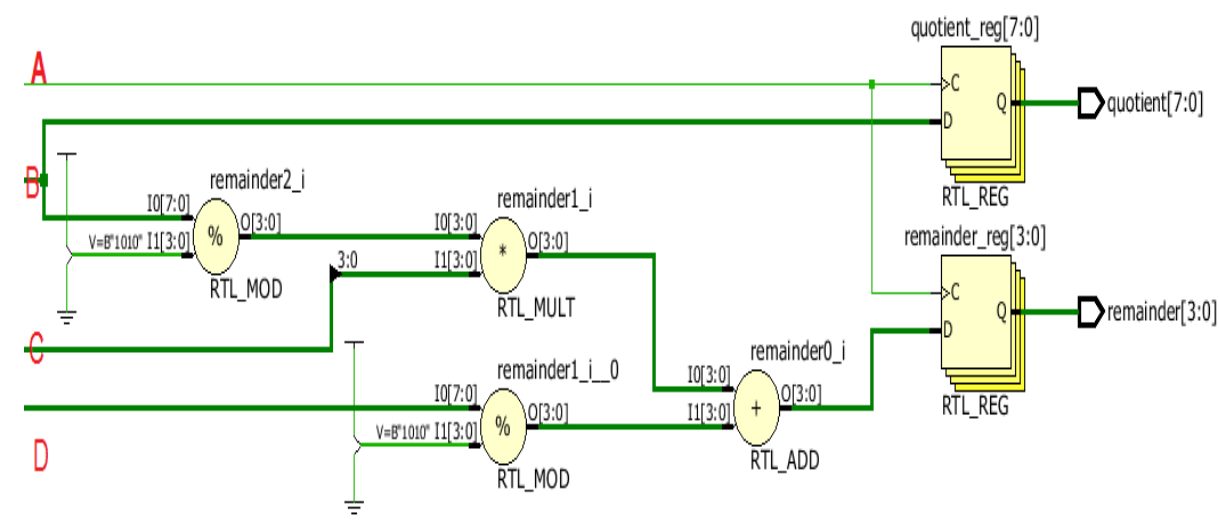

Fig. 7. RTL Schematic of Parvartya Yojayet: Part II

Step 4: Take Mod of 21 and 10 and multiply 1 (i.e.21\%10) with -2 and add final result -2 in remainder 4 (in step 1) and final remainder is 2 as shown in Figure 7. 


\section{Power Analysis of Vedic Divider on Kintex-7 FPGA}

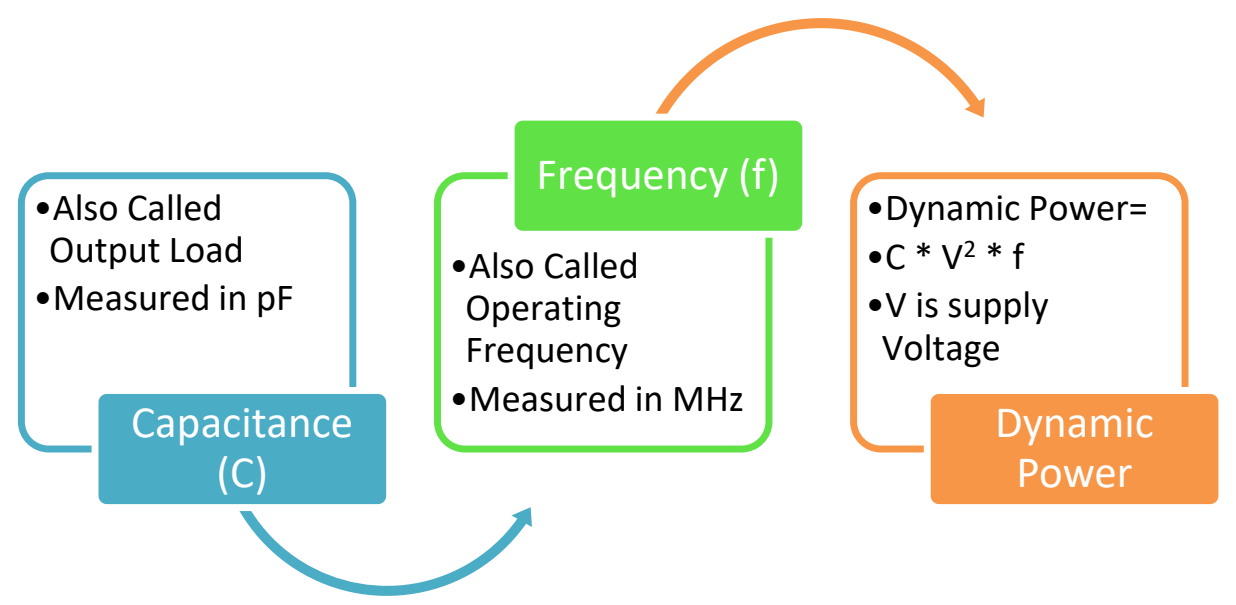

Fig. 8. Role of Capacitance and Frequency in Dynamic Power Dissipation

Dynamic power is directly proportional to capacitance and frequency as shown in Fig.8. When we scale down capacitance, power dissipation will decrease in same proportion. Ambient temperature is constant 25 degree Celsius. Airflow is 250 LFM. LFM is Linear Feet per Minute. Unit of capacitance is pico Farad (pF).

\subsection{Power Analysis of Vedic Divider for $1400 \mathrm{MHz}$ Operating Frequency}

Table 1. Power Analysis at $25^{\circ}$ Celsius Ambient Temperature and 250 LFM Airflow

\begin{tabular}{|c|c|}
\hline Capacitance in $\mathrm{pF}$ & Total Power \\
\hline $20 \mathrm{pF}$ & 1.567 \\
\hline $40 \mathrm{pF}$ & 2.470 \\
\hline $60 \mathrm{pF}$ & 3.373 \\
\hline $80 \mathrm{pF}$ & 4.276 \\
\hline $100 \mathrm{pF}$ & 5.179 \\
\hline
\end{tabular}

There is $69.74 \%$ reduction in total power dissipation when we use $28 \mathrm{~nm}$ FPGA and capacitance is scaled down from $100 \mathrm{pF}$ to $20 \mathrm{pF}$ as shown in Table 1 and Fig. 9. Here, 
Gyancity Journal of Engineering and Technology,

Vol.2, No.1, pp. 19-33, January 2016

ISSN: 2456-0065 DOI: 10.21058/gjet.2016.2103

device operating frequency is constant $1400 \mathrm{MHz}$. So, power is changing with change in capacitance.

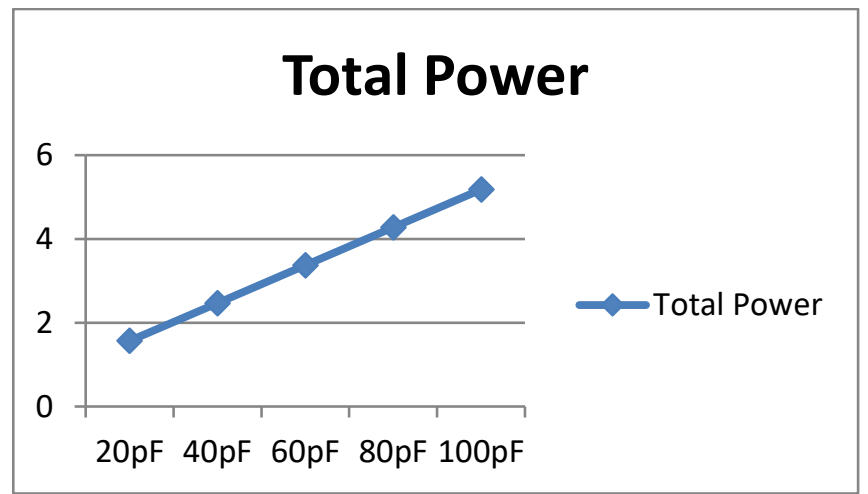

Fig. 9. Power Dissipation at $25^{\circ} \mathrm{Celsius}$ Temperature and $1400 \mathrm{MHz}$ Frequency

\subsection{Power Analysis for $1.2 \mathrm{GHz}$ Device Operating Frequency}

Here, device operating frequency is constant $1200 \mathrm{MHz}$, airflow is also constant 250 LFM, and ambient temperature is also constant 25 degree Celsius. So, power is decreasing with decrease in capacitance. Unit of power is Watt (W) and unit of Capacitance is pico Farad (pF). Pico is unit that is $10^{-12}$ in magnitude.

Table 2. Power Analysis at $25^{\circ}$ Celsius Ambient Temperature and 250 LFM Airflow

\begin{tabular}{|c|c|}
\hline Capacitance in $\mathrm{pF}$ & Total Power \\
\hline $20 \mathrm{pF}$ & 1.317 \\
\hline $40 \mathrm{pF}$ & 2.068 \\
\hline $60 \mathrm{pF}$ & 2.819 \\
\hline $80 \mathrm{pF}$ & 3.570 \\
\hline $100 \mathrm{pF}$ & 4.322 \\
\hline
\end{tabular}

There is $69.52 \%$ reduction in total power dissipation when we use $28 \mathrm{~nm}$ FPGA and capacitance is scaled down from $100 \mathrm{pF}$ to $20 \mathrm{pF}$ as shown in Table 2 and Fig. 10 . 
Gyancity Journal of Engineering and Technology,

Vol.2, No.1, pp. 19-33, January 2016

ISSN: 2456-0065 DOI: 10.21058/gjet.2016.2103

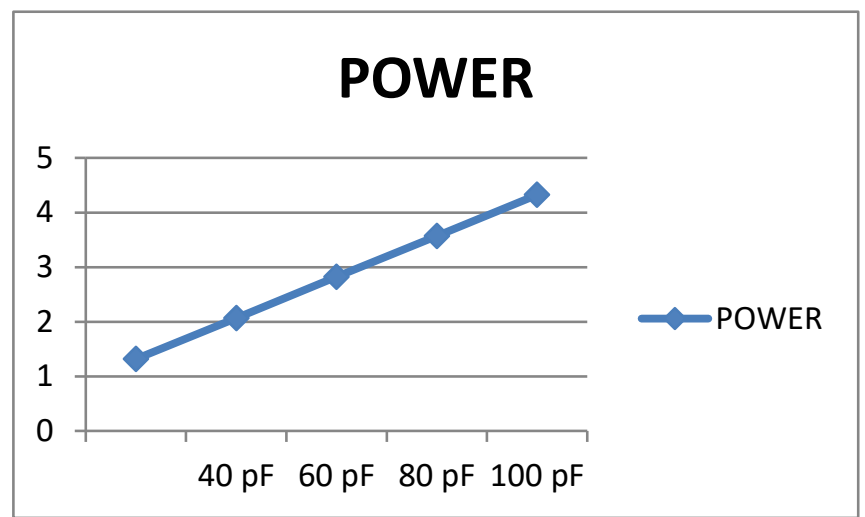

Fig. 10. Power Dissipation at $25^{\circ} \mathrm{Celsius}$ Temperature and $1.2 \mathrm{GHz}$ Frequency

\subsection{Power Analysis for $2100 \mathrm{MHz}$ Device Operating Frequency}

Here, device operating frequency is constant $2100 \mathrm{MHz}$, airflow is also constant 250 LFM, and ambient temperature is also constant 25 degree Celsius. So, power is decreasing with decrease in capacitance. Unit of power is Watt (W) and unit of Capacitance is pico Farad ( $\mathrm{pF})$. Pico is unit that is $10^{-12}$ in magnitude.

Table 3. Power Analysis at $25^{\circ}$ Celsius Ambient Temperature and 250 LFM Airflow

\begin{tabular}{|c|c|}
\hline Capacitance in $\mathrm{pF}$ & Total Power \\
\hline $20 \mathrm{pF}$ & 2.414 \\
\hline $40 \mathrm{pF}$ & 3.830 \\
\hline $60 \mathrm{pF}$ & 5.248 \\
\hline $80 \mathrm{pF}$ & 6.666 \\
\hline $100 \mathrm{pF}$ & 8.085 \\
\hline
\end{tabular}

There is $70.14 \%$ reduction in total power dissipation when we use $28 \mathrm{~nm}$ FPGA and temperature is 25 degree Celsius and capacitance is scaled down from $100 \mathrm{pF}$ to $20 \mathrm{pF}$ as shown in Table 3 and Fig. 11. 
Gyancity Journal of Engineering and Technology,

Vol.2, No.1, pp. 19-33, January 2016

ISSN: 2456-0065 DOI: 10.21058/gjet.2016.2103

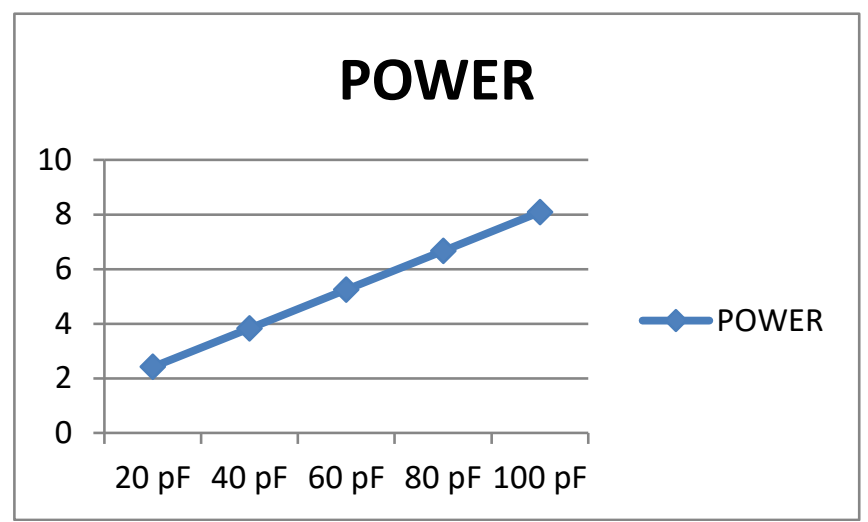

Fig. 11. Power Dissipation at $25^{\circ} \mathrm{Celsius}$ Temperature and $2100 \mathrm{MHz}$ Frequency

\subsection{IO Power Analysis for $1700 \mathrm{MHz}$ Device Operating Frequency}

Here, device operating frequency is constant $1700 \mathrm{MHz}$, airflow is also constant 250 LFM, and ambient temperature is also constant 25 degree Celsius. So, power is decreasing with decrease in capacitance. Unit of power is Watt (W) and unit of Capacitance is pico Farad (pF). Pico is unit that is $10^{-12}$ in magnitude.

Table 4. Power Analysis at $25^{\circ}$ Celsius Ambient Temperature and 250 LFM Airflow

\begin{tabular}{|c|c|}
\hline Capacitance in $\mathrm{pF}$ & Total Power \\
\hline $20 \mathrm{pF}$ & 1.922 \\
\hline $40 \mathrm{pF}$ & 3.040 \\
\hline $60 \mathrm{pF}$ & 4.426 \\
\hline $80 \mathrm{pF}$ & 5.618 \\
\hline $100 \mathrm{pF}$ & 6.810 \\
\hline
\end{tabular}

There is $71.77 \%$ reduction in total power dissipation when we use 28nm FPGA and temperature is 25 degree Celsius and capacitance is scaled down from $100 \mathrm{pF}$ to $20 \mathrm{pF}$ as shown in Table 4 and Fig. 12. 
Gyancity Journal of Engineering and Technology,

Vol.2, No.1, pp. 19-33, January 2016

ISSN: 2456-0065 DOI: 10.21058/gjet.2016.2103

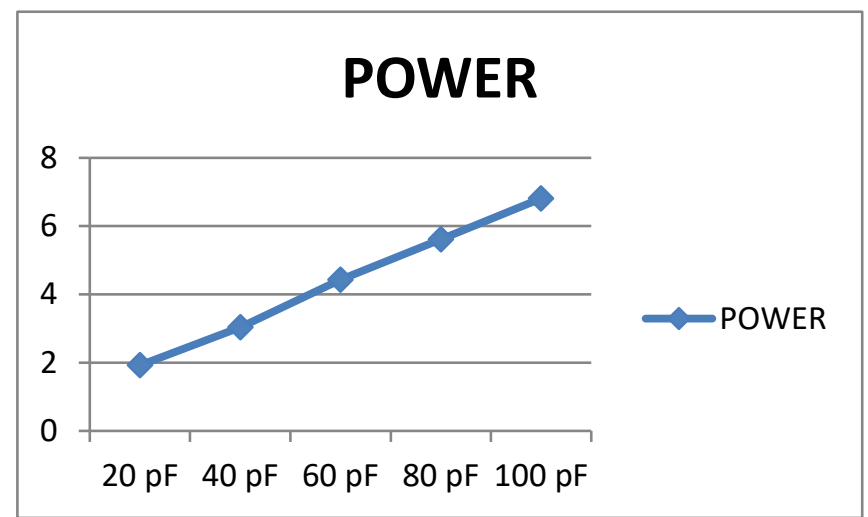

Fig. 12. Power Dissipation at $25^{\circ}$ Celsius Temperature and $1700 \mathrm{MHz}$ Frequency

\subsection{Power Analysis for $1800 \mathrm{MHz}$ Device Operating Frequency}

Here, device operating frequency is constant $1800 \mathrm{MHz}$, airflow is also constant 250 LFM, and ambient temperature is also constant 25 degree Celsius. So, power is decreasing with decrease in output load. Unit of power is Watt (W) and unit of Capacitance is pico Farad (pF). Pico is unit that is $10^{-12}$ in magnitude. Capacitance is also called output load.

Table 5. Power Analysis at $25^{\circ}$ Celsius Ambient Temperature and 250 LFM Airflow

\begin{tabular}{|c|c|}
\hline Capacitance in $\mathrm{pF}$ & Total Power \\
\hline $20 \mathrm{pF}$ & 2.043 \\
\hline $40 \mathrm{pF}$ & 3.234 \\
\hline $60 \mathrm{pF}$ & 4.426 \\
\hline $80 \mathrm{pF}$ & 5.618 \\
\hline $100 \mathrm{pF}$ & 6.810 \\
\hline
\end{tabular}

There is $70 \%$ reduction in total power dissipation when we use 28nm FPGA and temperature is 25 degree Celsius and capacitance is scaled down from $100 \mathrm{pF}$ to $20 \mathrm{pF}$ as shown in Table 6 and Fig. 14. 
Gyancity Journal of Engineering and Technology,

Vol.2, No.1, pp. 19-33, January 2016

ISSN: 2456-0065 DOI: 10.21058/gjet.2016.2103

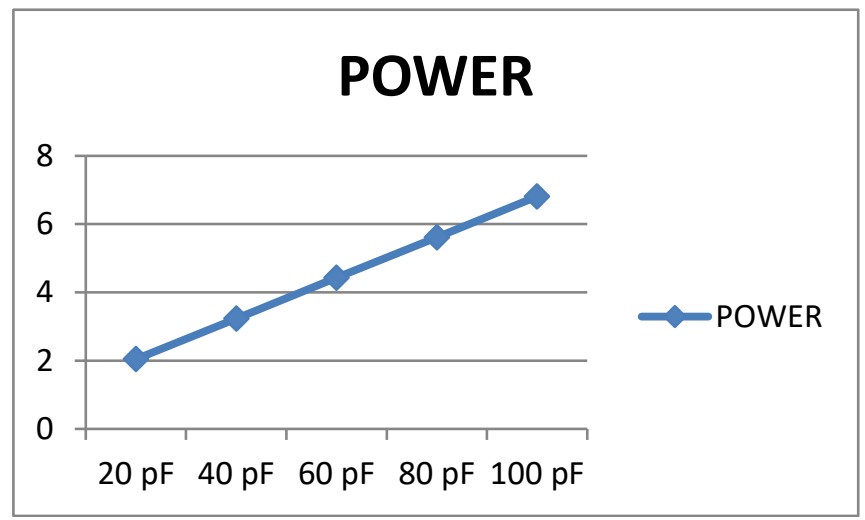

Fig. 13. Power Dissipation at $25^{\circ}$ Celsius Temperature for $1800 \mathrm{MHz}$ Frequency

\subsection{Power Analysis for 2.2 GHz Device Operating Frequency}

Here, device operating frequency is constant $2200 \mathrm{MHz}$, airflow is also constant 250 LFM, and outside environment temperature is 25 degree Celsius. Therefore, power is increasing with increase in capacitance. Unit of power is Watt (W) and unit of Capacitance is pico Farad (pF). Pico is unit that is $10^{-12}$ in magnitude.

Table 6. Power Analysis at $25^{\circ}$ Celsius Ambient Temperature and 250 LFM Airflow

\begin{tabular}{|c|c|}
\hline Capacitance in $\mathrm{pF}$ & Total Power \\
\hline $20 \mathrm{pF}$ & $2.541 \mathrm{~W}$ \\
\hline $40 \mathrm{pF}$ & $4.034 \mathrm{~W}$ \\
\hline $60 \mathrm{pF}$ & $5.528 \mathrm{~W}$ \\
\hline $80 \mathrm{pF}$ & $7.023 \mathrm{~W}$ \\
\hline $100 \mathrm{pF}$ & $8.519 \mathrm{~W}$ \\
\hline
\end{tabular}

There is $70.17 \%$ reduction in total power dissipation when we use $28 \mathrm{~nm}$ FPGA and temperature is 25 degree Celsius and capacitance is scaled down from $100 \mathrm{pF}$ to $20 \mathrm{pF}$ as shown in Table 6 and Fig. 14. 
Gyancity Journal of Engineering and Technology,

Vol.2, No.1, pp. 19-33, January 2016

ISSN: 2456-0065 DOI: 10.21058/gjet.2016.2103

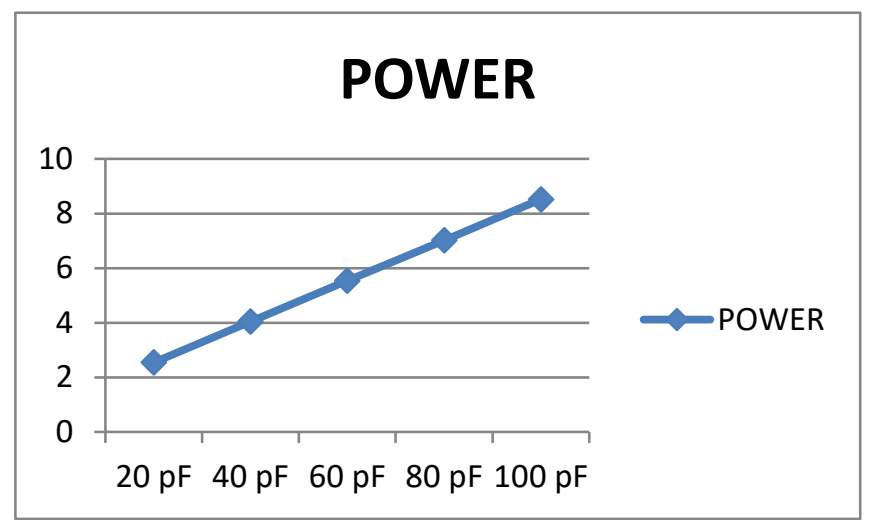

Fig. 14. Power Dissipation at $25^{\circ} \mathrm{Celsius}$ Temperature for $2.2 \mathrm{GHz}$ Frequency

\subsection{Power Analysis for Different Frequencies at Different Capacitance}

Table 7. Power Dissipation of Vedic Divider at $25^{\circ} \mathrm{C}$ Temperature, and $250 \mathrm{LFM}$ Airflow

\begin{tabular}{|l|l|l|l|l|l|}
\hline Frequency & $20 \mathrm{pF}$ & $40 \mathrm{pF}$ & $60 \mathrm{pF}$ & $80 \mathrm{pF}$ & $100 \mathrm{pF}$ \\
\hline $1400 \mathrm{MHz}$ & 1.567 & 2.470 & 3.373 & 4.276 & 5.179 \\
\hline $1.2 \mathrm{GHz}$ & 1.317 & 2.068 & 2.819 & 3.570 & 4.322 \\
\hline $2100 \mathrm{MHz}$ & 2.414 & 3.830 & 5.248 & 6.666 & 8.085 \\
\hline $1700 \mathrm{MHz}$ & 1.922 & 3.040 & 4.426 & 5.618 & 6.810 \\
\hline $1800 \mathrm{MHz}$ & 2.043 & 3.234 & 4.426 & 5.618 & 6.810 \\
\hline $2.2 \mathrm{GHz}$ & 2.541 & 4.034 & 5.528 & 7.023 & 8.519 \\
\hline
\end{tabular}

Table 7 and Fig. 15 tells us that the maximum power is consumed at $2.2 \mathrm{GHz}$ and minimum power is consumed at $1.2 \mathrm{GHz}$. In respect of capacitance maximum power is consumed at $100 \mathrm{pF}$ and minimum power is consumed at $20 \mathrm{pF}$.

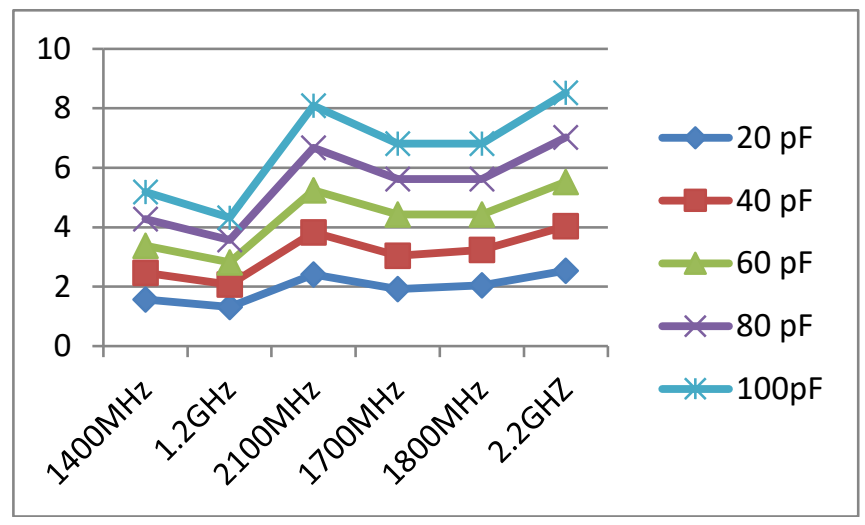




\section{Gyancity Journal of Engineering and Technology, \\ Vol.2, No.1, pp. 19-33, January 2016 \\ ISSN: 2456-0065 DOI: 10.21058/gjet.2016.2103}

Fig. 15. Power Dissipation at $25^{\circ} \mathrm{Celsius}$ Temperature for Different Frequencies and Capacitances

\section{Conclusion}

The design is energy efficient and the code has been implemented in Xilinx ISE Design Suite 14.2 and results were tested on 28nm FPGA platform. This Vedic divider consists of 2 inputs that are dividend and divisor and 2 outputs that are remainder and quotient. The design is tested by varying capacitance at different frequencies keeping the temperature constant that is 25 degree Celsius. We can conclude from this design that the maximum power is consumed at $2.2 \mathrm{GHz}$ and minimum power is consumed at $1.2 \mathrm{GHz}$. In respect of capacitance maximum power is consumed at $100 \mathrm{pF}$ and minimum power is consumed at $20 \mathrm{pF}$.

\section{$4 \quad$ Future Scope}

The future scope of Capacitance Scaling Based Energy Efficient Vedic divider using ParavartyaYojayet on 28nm FGPA is that we have used 28nm FGPA that is Kintex-7. We can also implement this design on $22 \mathrm{~nm}$ or $18 \mathrm{~nm}$ FGPA. We can also use different FGPA families like automotive Artix7, automotive Coolrunner2, automotive Spartan, automotive Spartan-3A DSP, automotive Spartan 3A, automotive Spartan 3E, automotive Spartan6, Spartan3, Spartan3E.Here, we are using capacitance scaling techniques. We can redesign this Vedic divider with other energy efficient technique like frequency scaling, thermal scaling, clock gating, and impedance matching with different logic family, and mapping. We can also change values of frequencies and can change the range of capacitance.

\section{References}

[1] Thapliyal, H., and Arabnia, H.R. (2004). A Time-Area-Power Efficient Multiplier and Square Architecture Based on Ancient Indian Vedic Mathematics. Proceedings of the 2004 International Conference on VLSI (VLSI'04: Las Vegas, USA), pp. 434-439.

[2] Kumar, U. C. S. P., Goud, A. S. and Radhika, A. (2013). FPGA Implementation of high speed 8-bit Vedic multiplier using barrel shifter. IEEE International Conference on. Energy Efficient Technologies for Sustainability (ICEETS).

[3] Soma, B.T. Vedic divider-A high performance computing algorithm for VLSI applications. IEEE International conference on Circuits, Controls and Communications (CCUBE), 2013. IEEE, 2013.

[4] Tirtha, Swami Bharati Krishna. Vedic mathematics. Vol. 10. Motilal Banarsidass Publ., 1992.

[5] Kumar, Alok. Vedic Mathematics Sutra. Upkar Prakashan, 2008.

[6] Itawadiya, A. K., et al. (2013). Design a DSP operations using vedic mathematics. IEEE International Conference on Communications and Signal Processing (ICCSP). 


\section{Gyancity Journal of Engineering and Technology, \\ Vol.2, No.1, pp. 19-33, January 2016 \\ ISSN: 2456-0065 DOI: 10.21058/gjet.2016.2103}

[7] Deepthi, P., and Chakravarthi, V.S. (2014). Design of novel Vedic asynchronous digital signal processor core. 2nd IEEE International Conference on Devices, Circuits and Systems (ICDCS), 2014.

[8] Kundu, D. K., et al. (2014). Implementation of optimized high performance $4 \times 4$ multiplier using ancient Vedic sutra in $45 \mathrm{~nm}$ technology. 2nd IEEE International Conference on Devices, Circuits and Systems (ICDCS), 2014.

[9] Oke, S., Lulla,S. and Lad, P. (2014). VLSI (FPGA) design for distinctive division architecture using the Vedic sutra 'Dhwajam'. 2nd IEEE International Conference on Devices, Circuits and Systems (ICDCS).

[10] Goswami, K., Pandey, B. (2014). LVCMOS Based Thermal Aware Energy Efficient Vedic Multiplier Design on FPGA. IEEE 6th International Conference on Computational Intelligence and Communication Networks (CICN).

[11] Goswami, K., Pandey, B. (2014). Energy Efficient Vedic Multiplier Design Using LVCMOS and HSTL IO Standard, IEEE 9th International Conference on Industrial and Information Systems (ICIIS).

[12] Bansal, M. et.al. (2014). FPGA Based Low Power ROM Design Using Capacitance Scaling. Advanced Materials Research, Trans Tech Publications, Switzerland, (SCOPUS Indexed).

[13] Singh, P., et.al. (2014). Output Load Capacitance Based Low Power Implementation of UART on FPGA. IEEE International Conference on Computer Communication and Informatics (ICCCI). DOI: 10.1109/ICCCI.2014.6921826

[14] Banshal, S., (2014). Capacitance Scaling Aware Power Optimized Register Design And Implementation on 28nm FPGA. IEEE International Conference on Computer Communication and Informatics (ICCCI). DOI: 10.1109/ICCCI.2014.6921838. 